\title{
Author's reply re: Vesicular mole in a twin pregnancy. (Response to BJOG-20-2361)
}

\author{
Amarnath Bhide ${ }^{1}$ \\ ${ }^{1}$ St Georges university Hospitals
}

December 1, 2020

Letter to the Editor, BJOG Exchange

Author's reply re: Vesicular mole in a twin pregnancy

Sir,

We thank Tsz-Kin Lo for the interest in the mini-commentary ${ }^{1,2}$. The issues raised by the author are valid. Indeed, the purpose of the mini-commentary was to elaborate on the similarities and differences between vesicular mole in a twin pregnancy, placental mesenchymal dysplasia (PMD) and a partial vesicular mole. The mini-commentary states that trophoblastic proliferation and stromal inclusions are not seen in PMD, implying that the distinction is possible only on pathology. I thank the author for making this explicit. Histopathological diagnosis is unfortunately available only in retrospect. The suggestion to consider amniocentesis for molecular diagnosis of Beckwith-Wiedemann syndrome in a case of suspected complete vesicular mole and an apparently normal fetus in a twin pregnancy signals the challenges of antenatal diagnosis. Such a consideration would be unnecessary if one were to be sure of the diagnosis without the availability of placental histopathology.

Ultrasound is the most common modality for prenatal diagnosis of vesicular mole in a twin pregnancy ${ }^{2}$. MRI has been described for the detection of molar placenta and a sac separating from fetus and normal placenta in a case of vesicular mole in a twin pregnancy. This would be helpful to differentiate it from PMD or a partial mole with a co-existing fetus. Another possibility is a sub-chorionic haematoma, with which it is confused not infrequently ${ }^{3}$. However, there are no studies that have investigated the diagnostic accuracy of MR imaging compared to ultrasound in complete vesicular mole with a co-existing fetus ${ }^{4}$.

An international consensus statement reported that CVS cells might not reflect the (epi)genetic constitution of the fetus, and therefore, false-positive results might occur ${ }^{5}$. Hence, amniocentesis is the more reliable investigation for imprinting disorders such as Beckwith-Wiedemann syndrome.

The criticism of over-simplification/generalisation is accepted. The intention was to state common associations and outcomes, not the exceptional ones.

Amarnath Bhide

Fetal Medicine Unit

St George's University Hospitals NHS Foundation Trust

London

\section{References}

1. Lo, Tsz Kin. Re: Vesicular mole in a twin pregnancy. (First comment letter. Reference to be added). 
2. Bhide A. Vesicular mole in a twin pregnancy. BJOG. 2020 Nov;127(12):1458.

3. Giorgione V, Cavoretto P, Cormio G, Valsecchi L, Vimercati A, De Gennaro A, et al. Prenatal Diagnosis of Twin Pregnancies with Complete Hydatidiform Mole and Coexistent Normal Fetus: A Series of 13 Cases. Gynecol Obstet Invest. 2017;82(4):404-9.

4. Imafuku H, Miyahara Y, Ebina Y, Yamada H. Ultrasound and MRI Findings of Twin Pregnancies with Complete Hydatidiform Mole and Coexisting Normal Fetus: Two Case Reports. Kobe J Med Sci. 2018 May 28;64(1):E1-E5.

5. Brioude F, Kalish JM, Mussa A, Foster AC, Bliek J, Ferrero GB, et al. Expert consensus document: Clinical and molecular diagnosis, screening and management of Beckwith-Wiedemann syndrome: an international consensus statement. Nat Rev Endocrinol. 2018 Apr;14(4):229-49. 